\title{
Tratamento de Poluentes Orgânicos pelo Processo de Oxidação Catalítica com Peróxido de Hidrogénio: História, Motivações E TENDÊNCIAS
}

\author{
Rui S. Ribeiro ${ }^{a, b}$, Adrián M. T. Silva ${ }^{b}$, Joaquim L. Faria ${ }^{b}$, Helder T. Gomes,a,b, \\ ${ }^{a}$ Departamento de Tecnologia Química e Biológica, Escola Superior de Tecnologia e Gestão, Instituto Politécnico de Bragança \\ ${ }^{\mathrm{b}}$ LCM - Laboratório de Catálise e Materiais - Laboratório Associado LSRE/LCM, Faculdade de Engenharia, Universidade do Porto \\ htgomes@ipb.pt
}

\begin{abstract}
A síntese de compostos orgânicos cada vez mais complexos tem levado ao aumento do número de poluentes que subsistem após os processos convencionais de tratamento biológico de águas residuais. Para promover a efectiva destruição destes poluentes surgem, como alternativa, os processos avançados de oxidação, entre os quais se inclui a oxidação catalítica com peróxido de hidrogénio (catalytic wet peroxide oxidation - CWPO). Este processo consiste na geração, e subsequente utilização, do radical hidroxilo através da decomposição catalisada de peróxido de hidrogénio. De forma a analisar as actuais tendências na investigação realizada para o tratamento de compostos orgânicos presentes em solução aquosa pelo processo de CWPO, é apresentada neste artigo uma perspectiva histórica das principais motivações que têm dado origem a progressos relevantes nesta área. O principal enfoque é dado ao desenvolvimento de catalisadores, sendo identificadas as suas principais caraterísticas, vantagens e limitações, bem como apresentados resultados obtidos e mecanismos envolvidos quando utilizados tanto catalisadores homogéneos como heterogéneos. Conclui-se que a tendência nesta área de investigação incide sobre o desenvolvimento de materiais de carbono sem espécies metálicas suportadas e na síntese de materiais compósitos contendo espécies de ferro na sua composição.
\end{abstract}

\section{INTRODUÇÃO}

Desde sempre a natureza foi encarada como uma fonte inesgotável de recursos. Contudo sabe-se que a água potável - um recurso indissociável da existência da Humanidade - é na realidade esgotável. Com a constituição de aglomerados populacionais de densidade significativa, a capacidade de autodepuração da natureza começou a ser insuficiente, surgindo problemas e dificuldades na satisfação das necessidades de água em condições apropriadas para as actividades do ser humano. Neste contexto surgiram as estações de tratamento de águas residuais (ETARs), que desempenham um papel preponderante na reintegração nos meios naturais das águas residuais tratadas. Os métodos convencionais de tratamento desenvolvidos em ETARs baseiam-se essencialmente em processos biológicos aeróbios, nos quais os compostos orgânicos biodegradáveis presentes nas águas residuais são utilizados como nutrientes para o metabolismo celular de culturas microbianas, dando maioritariamente origem a produtos que são inócuos para o meio que recebe a água tratada [1]. Contudo, à medida que se desenvolvem novas formulações cada vez mais complexas e biorecalcitrantes, aumenta também o número de poluentes que subsistem após os processos convencionais de tratamento biológico. Alguns podem inclusive provocar efeitos nefastos sobre as culturas microbianas devido à respectiva toxicidade [2]. Tradicionalmente, uma solução para este tipo de poluentes é a sua transferência da fase líquida para uma fase sólida - via adsorção. Contudo, no sentido de promover a destruição efectiva destes poluentes, e não apenas a sua transferência para um substrato, começaram a surgir os processos avançados de oxidação, normalmente associados à geração, em solução, do radical hidroxilo (HO), cujo potencial oxidante é bastante ele- vado. Estes processos têm sido especialmente relevantes para tratamento de águas residuais de origem industrial. A oxidação catalítica com peróxido de hidrogénio (CWPO) é um processo avançado de oxidação que utiliza peróxido de hidrogénio $\left(\mathrm{H}_{2} \mathrm{O}_{2}\right)$ como oxidante que, na presença de um catalisador adequado, potencia a produção do radical HO'. É um processo especialmente atractivo por recorrer a condições de operação moderadas, próximas das condições ambientais, utilizando equipamento simples e um oxidante praticamente inócuo em termos de impacto ambiental [3].

Tendo em consideração que o conceito de catalisador está hoje firmemente enraizado no vocabulário corrente da população, no presente trabalho é apresentada uma análise sintética e com perspectiva histórica das principais motivações para a enorme progressão na área do desenvolvimento de catalisadores para o processo de CWPO. Nesta abordagem são introduzidos conceitos, descritos materiais e aplicações que têm sido inseridos nos programas de estudo das ciências. Por fim, são apresentados nesta temática alguns resultados experimentais obtidos pelo nosso grupo de investigação.

\section{Processo de Fenton}

No final do século XIX, o investigador britânico H. Fenton tornou público o seu trabalho sobre a oxidação do ácido tartárico na presença de sulfato de ferro(II) [4]. Nesse trabalho demonstrou-se que na presença de pequenas quantidades de ião ferroso $\left(\mathrm{Fe}^{2+}\right)$, o ácido tartárico é oxidado pela interacção com certos agentes oxidantes, tendo o $\mathrm{H}_{2} \mathrm{O}_{2}$ apresentado os melhores resultados. Já então H. Fenton descreveu a actuação do $\mathrm{Fe}^{2+}$ no processo como sendo provavelmente catalítica, dado que uma pequena quantidade 
deste ião se revelava suficiente para promover a remoção completa do ácido tartárico sem que se observasse o seu consumo durante o processo.

Cerca de quatro décadas depois, em 1934, F. Haber e J. Weiss deram um importante contributo para a compreensão do fenómeno reportado por $\mathrm{H}$. Fenton, ao sugerirem que o agente efectivamente responsável pela oxidação seria o radical $\mathrm{HO}^{*}$, formado durante a decomposição do $\mathrm{H}_{2} \mathrm{O}_{2}$ [5]. Segundo os autores, a interacção entre $\mathrm{H}_{2} \mathrm{O}_{2}$ e $\mathrm{Fe}^{2+}$ em meio ácido leva à decomposição do $\mathrm{H}_{2} \mathrm{O}_{2}$, servindo este como agente responsável pela oxidação do $\mathrm{Fe}^{2+}$ a ião férrico $\left(\mathrm{Fe}^{3+}\right)$, com a consequente formação de ião hidróxido $\left(\mathrm{OH}^{-}\right)$e do radical HO', num mecanismo desenvolvido de acordo com a Equação 1.

$$
\mathrm{H}_{2} \mathrm{O}_{2}+\mathrm{Fe}^{2+} \rightleftarrows \mathrm{OH}^{-}+\mathrm{HO}^{\cdot}+\mathrm{Fe}^{3+}
$$

Posteriormente, em meados do século Xx, W. Barb et al. apresentaram um mecanismo mais complexo para a decomposição do $\mathrm{H}_{2} \mathrm{O}_{2}$ na presença de $\mathrm{Fe}^{2+}$ em solução aquosa, identificando e corrigindo algumas lacunas existentes em mecanismos publicados até então [6,7]. Passou assim a estar explicada a participação deste ião como catalisador na decomposição do $\mathrm{H}_{2} \mathrm{O}_{2}$, uma vez que durante o processo é regenerado de acordo com uma sequência de reacções, das quais se destacam:

- numa primeira fase, o $\mathrm{H}_{2} \mathrm{O}_{2}$ em solução pode reagir com o radical $\mathrm{HO}^{*}$ gerado segundo a Equação 1, dando origem ao radical hidroperoxilo (HOO*), Equação 2;

- o recém-formado radical HOO reduz o ião $\mathrm{Fe}^{3+}$ existente em solução a $\mathrm{Fe}^{2+}$, fechando assim o ciclo de regeneração do catalisador, Equação 3.

$$
\begin{aligned}
& \mathrm{H}_{2} \mathrm{O}_{2}+\mathrm{HO}^{\bullet} \rightarrow \mathrm{HOO}^{\circ}+\mathrm{H}_{2} \mathrm{O} \\
& \mathrm{Fe}^{3+}+\mathrm{HOO}^{\bullet} \rightarrow \mathrm{O}_{2}+\mathrm{H}^{+}+\mathrm{Fe}^{2+}
\end{aligned}
$$

À luz do conhecimento actual é sabido que o radical HO' possui um elevado potencial padrão de redução (+2,8 V, em relação ao eléctrodo padrão de hidrogénio), sendo a espécie oxidante mais forte depois do flúor (que possui um potencial padrão de redução de $+3,0 \mathrm{~V}$ ). Este potencial, aliado a uma constante de difusão elevada em solução aquosa, torna-o uma espécie altamente eficaz na destruição de uma ampla gama de poluentes [8,9], a comprovar a eficácia deste processo na mineralização completa (conversão a dióxido de carbono e água) de vários compostos orgânicos que não são passíveis de remoção através de processos biológicos convencionais.

Uma motivação adicional para a utilização do $\mathrm{H}_{2} \mathrm{O}_{2}$ como fonte do radical $\mathrm{HO}^{\star}$ advém do facto desta molécula ser praticamente inócua em termos de impactos ambientais, já que a sua decomposição não catalítica apenas origina oxigénio e água [3,10], como descrito pela Equação 4.

$\mathrm{H}_{2} \mathrm{O}_{2} \rightarrow 1 / 2 \mathrm{O}_{2}+\mathrm{H}_{2} \mathrm{O}$
Contudo, apesar dos resultados reconhecidos em termos de remoção de poluentes orgânicos e do reduzido custo (em comparação com processos que requerem condições de temperatura e de pressão mais elevadas, ou oxidantes de custo superior), existem alguns condicionalismos e entraves à utilização generalizada do processo de Fenton. Estes resultam, sobretudo, da utilização de espécies de ferro que conduzem à ocorrência deste metal em concentrações superiores às autorizadas pelas Directivas Europeias para águas residuais tratadas - no caso português, o valor limite na descarga de águas residuais cifra-se em $2 \mathrm{mg} \mathrm{L}^{-1}$ [11]. É por isso quase sempre necessária a implementação de uma etapa suplementar de separação química dos iões $\mathrm{Fe}^{2+}$ e $\mathrm{Fe}^{3+}$, o que por sua vez gera lamas residuais que normalmente têm como destino aterros sanitários.

Adicionalmente há que ter em conta o facto do processo de Fenton requerer condições ácidas, habitualmente na gama de pH entre 2,5 e 4 [12]. Considerando as restrições legalmente estabelecidas em relação aos valores de $\mathrm{pH}$ a que as águas residuais tratadas podem ser descarregadas no meio natural - entre 6 e 9 no caso português [11] - a elevada acidez associada ao processo de Fenton implica uma etapa suplementar de neutralização, decorrente da etapa prévia de acidificação, que leva a constantes modificações do pH e como consequência ao consumo de quantidades elevadas de reagentes químicos.

Em suma, o processo de Fenton permite a destruição da generalidade dos compostos orgânicos, com custos relativamente reduzidos, mas os impactos ambientais decorrentes da existência de iões $\mathrm{Fe}^{2+}$ e $\mathrm{Fe}^{3+}$ nos ciclos naturais de água e a necessidade da sua recuperação exige que se considerem alternativas à sua utilização. A mais óbvia até à data passou pelo desenvolvimento de sistemas catalíticos heterogéneos contendo as espécies de ferro imobilizadas na sua estrutura [13].

\section{CATAlisadores heterogÉneOS COM ESPÉCIES METÁLICAS SUPORTADAS}

Em 1984, um artigo de revisão de P. Ehrburger chamou a atenção para as vantagens da utilização de materiais de carbono na preparação de catalisadores metálicos heterogéneos [13]. Desde essa data a quantidade de publicações na área tem aumentado de forma expressiva. A utilização de materiais de carbono, como são exemplo os carvões activados, carbon blacks (i.e., materiais de carbono resultantes da pirólise de hidrocarbonetos), nanotubos e nanofibras de carbono, como suporte para a preparação de catalisadores heterogéneos, acarreta diversas vantagens. Entre elas destaca-se o amplo conhecimento em técnicas de modificação das suas propriedades físico-químicas de superfície [14,15], permitindo o desenvolvimento de materiais com uma elevada área superficial, com uma estrutura porosa que facilite a difusão de reagentes e de produtos, e com características químicas adequadas para a dispersão de fases cataliticamente activas [13]. A principal vantagem decorrente da utilização de catalisadores com espécies de ferro suportadas - via catálise heterogénea - resulta do fac- 
to da etapa final de separação do catalisador da água residual tratada ser mais simples (ou mesmo evitada), já que a fase metálica activa se encontra imobilizada na superfície de um sólido que é facilmente separado da fase líquida por filtração ou por decantação. Deste modo também é facilitada a sua reutilização.

As técnicas mais utilizadas para a preparação de materiais de carbono com espécies metálicas suportadas têm como base o contacto do suporte com uma solução contendo o precursor da fase metálica activa - impregnação incipiente e impregnação com excesso de solução [13]. No primeiro caso o material de carbono é colocado em contacto com a solução do precursor na quantidade exactamente necessária para o preenchimento de todos os seus poros e no segundo caso utiliza-se um excesso de solução do precursor; no passo seguinte a mistura é seca para remover o solvente, ficando a fase metálica impregnada nas paredes do suporte. Em ambos os casos a impregnação é usualmente seguida de um tratamento térmico para activar a fase metálica [13]. No final podem resultar interacções bastante distintas entre a superfície do material de carbono e a fase activa, desde interacções electrostáticas fracas até reacções químicas.

Para o processo de CWPO, vários autores reportaram bons resultados obtidos com a utilização de catalisadores heterogéneos contendo espécies de ferro suportadas [16,17]. Todavia é reconhecida de igual modo a frequente instabilidade deste tipo de catalisadores, sobretudo devido à perda de actividade provocada pela lixiviação da fase activa para a solução que se está a tratar [16,17]. Assim, a extensão em que esta lixiviação ocorre constitui um ponto crítico que depende em parte do método utilizado para a preparação dos catalisadores heterogéneos [18]. Consequentemente, o desenvolvimento de catalisadores heterogéneos activos e ao mesmo tempo mais estáveis e duradouros, tem sido objecto de inúmeros estudos, incluindo a utilização de materiais de carbono como catalisadores sem qualquer fase metálica impregnada e a síntese de nanocompósitos contendo espécies metálicas na sua composição [18].

\section{MATERIAIS DE CARBONO COMO CATALISADORES HETEROGÉNE- OS SEM ESPÉCIES METÁLICAS SUPORTADAS}

Sobretudo desde o final da década de 90 do século XX, o interesse na utilização directa de materiais de carbono como catalisadores heterogéneos no processo de CWPO tem aumentado significativamente. Em 1998, F. Lücking et al. demonstraram que diferentes materiais de carbono são activos neste processo, podendo ser directamente utilizados como catalisadores heterogéneos sem que seja necessária a adição de qualquer espécie metálica [19]. Tanto a grafite como o carvão activado podem actuar como catalisadores heterogéneos na activação do $\mathrm{H}_{2} \mathrm{O}_{2}$ para a oxidação de poluentes orgânicos em solução aquosa [19]. Desde logo, a ausência de uma fase metálica foi reconhecida como a principal vantagem deste tipo de materiais, evitando-se assim a potencial contaminação da água tratada por espécies metálicas [19]. Para além disso é ainda evitada a perda de actividade por lixiviação frequentemente obser- vada em catalisadores heterogéneos com espécies metálicas suportadas.

Na última década, um número mais relevante de publicações científicas têm atestado a possibilidade de se utilizar materiais de carbono livres de espécies metálicas como catalisadores heterogéneos no processo de CWPO. O mecanismo envolvido assenta em três passos reaccionais, bastante semelhantes aos descritos para o processo de Fenton [18]:

- $\quad \mathrm{H}_{2} \mathrm{O}_{2}$ adsorvido é reduzido, originando o radical HO', numa etapa que envolve a participação de centros activos redutores [S] existentes na superfície do material de carbono (Equação 5);

- o radical $\mathrm{HO}^{*}$ recém-formado pode decompor a matéria orgânica, bem como reagir com o próprio $\mathrm{H}_{2} \mathrm{O}_{2}$ em solução, num processo de autoaniquilação descrito pela Equação 2, dando origem ao radical HOO;

- o radical HOO reduz os centros activos oxidados $\left[\mathrm{S}^{+}\right]$ existentes na superfície do material de carbono, de acordo com a Equação 6, fechando o ciclo de regeneração do catalisador.

Todas estas interacções estão representadas de forma sucinta na Figura 1.

$$
\begin{aligned}
& \mathrm{H}_{2} \mathrm{O}_{2}+[\mathrm{S}] \rightarrow \mathrm{OH}^{-}+\mathrm{HO}^{\bullet}+\left[\mathrm{S}^{+}\right] \\
& {\left[\mathrm{S}^{+}\right]+\mathrm{HOO}^{\bullet} \rightarrow \mathrm{O}_{2}+\mathrm{H}^{+}+[\mathrm{S}]}
\end{aligned}
$$

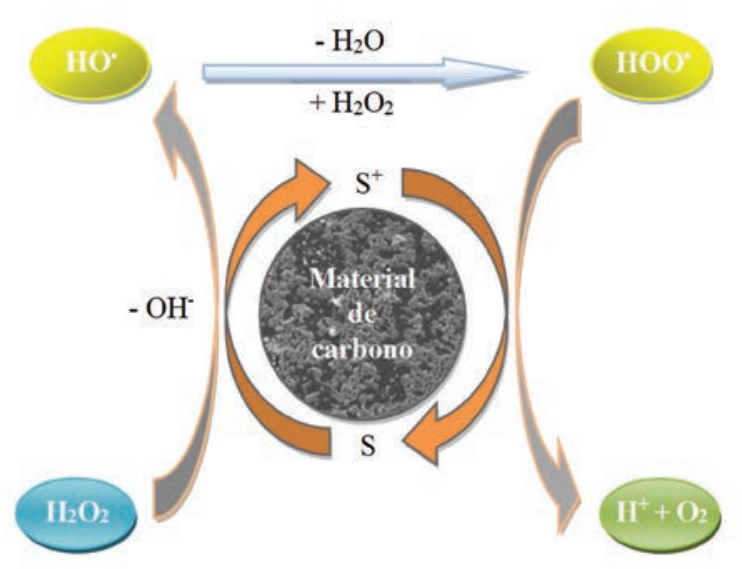

Figura 1 - Representação esquemática do mecanismo de geração do radical HO^ no processo de CWPO com a participação dos centros activos existentes à superfície de um material de carbono. Adaptado de [20]

Actualmente pode considerar-se que a grande limitação à aplicação generalizada de materiais de carbono como catalisadores heterogéneos para o processo de CWPO reside na sua aparente baixa actividade catalítica quando comparada com a obtida através da utilização de catalisadores à base de metais [21,22]. Não obstante, tendo em consideração que a decomposição do $\mathrm{H}_{2} \mathrm{O}_{2}$ no radical $\mathrm{HO}^{*}$ e em $\mathrm{OH}^{-}$envolve a transferência de electrões do centro redutor para a molécula de $\mathrm{H}_{2} \mathrm{O}_{2}$, é de esperar que a existência de 
electrões desemparelhados na superfície do material tenha um reflexo positivo na sua actividade catalítica [23]. Com o aprofundar do conhecimento sobre os mecanismos reaccionais envolvidos, a forma de superar a grande limitação apresentada passa pela modificação da química superficial dos materiais de carbono existentes ou pela síntese de novos materiais de carbono, intrinsecamente mais activos [24-27].

NANOCOMPÓSITOS CONTENDO ESPÉCIES DE FERRO NA SUA COMPOSIÇÃO

Os novos métodos de síntese de nanocompósitos à base de nanotubos de carbono ou de grafeno contendo espécies de ferro [28,29] poderão abrir uma janela de oportunidade para a utilização destes materiais como catalisadores no processo de CWPO. A inclusão intrínseca de espécies de ferro na estrutura do material poderá conter a lixiviação destas espécies para a solução tratada, evitando-se assim as principais limitações observadas quando estas espécies são suportadas. Nanocompósitos baseados em xerogéis de carbono já demonstraram a sua potencialidade neste tipo de processos de oxidação [30].

\section{REsultadOS EXPERIMENTAIS}

No “portfólio" de materiais de carbono potencialmente promissores para o processo de CWPO no tratamento de compostos orgânicos incluem-se materiais tão distintos como carvões activados, xerogéis de carbono, nanotubos de carbono e materiais de carbono sintetizados a partir de glicerol, que revelaram ser activos em vários estudos desenvolvidos pelo nosso grupo de investigação, mesmo na ausência de espécies de ferro ou de outros metais [20,24-26]. Uma vez que, em geral, estes materiais de carbono apresentam ele- vadas áreas superficiais (atingindo valores na ordem dos $1000 \mathrm{~m}^{2} \mathrm{~g}^{-1}$ ) [14,25], qualquer análise da sua actividade catalítica no processo de CWPO terá que ter em conta o fenómeno de adsorção da molécula do poluente alvo do tratamento, sobre a superfície do material de carbono. A Figura 2 apresenta os resultados obtidos em ensaios de CWPO e de adsorção, levados a cabo utilizando materiais de carbono com propriedades texturais e de química superficial bastante distintas, cuja descrição sumária se encontra na Tabela 1.

O objectivo da Figura 2 é evidenciar o efeito positivo do $\mathrm{H}_{2} \mathrm{O}_{2}$ na remoção de vários poluentes e demonstrar que os materiais em estudo são cataliticamente activos no processo de CWPO. Os resultados não devem ser comparados entre si porque foram obtidos em diferentes condições operatórias e visando a remoção de diferentes compostos orgânicos. Contudo, para o carvão activado (AC) e para o xerogel de carbono (RFX) pode verificar-se que as modificações induzidas na química superficial (i.e. os materiais com designação ACSA e ACXK, respectivamente) levaram a um aumento da actividade catalítica, o que vai de encontro ao referido anteriormente acerca do desenvolvimento de materiais sem metais que sejam catalisadores activos para o processo. Analogamente, materiais inovadores, como o produzido à base de glicerol (GBCM), ou mesmo nanotubos de carbono de paredes múltiplas (MWCNT), demonstraram ser potencialmente atractivos para utilização como catalisadores no tratamento de compostos orgânicos biorecalcitrantes, como é o caso do 2-nitrofenol (2-NP).

Um estudo mais detalhado efectuado recorrendo à utilização de diferentes catalisadores na decomposição de 2-NP pelo processo de CWPO (Figura 3) permite evidenciar claramente a evolução descrita ao longo do presente trabalho

Tabela 1 - Descrição sucinta de alguns materiais passíveis de utilização como catalisadores no processo de CWPO

\begin{tabular}{|c|c|c|}
\hline Catalisador & Designação & Origem / processo de preparação \\
\hline Carvão activado & $\mathrm{AC}$ & Norit ROX 0,8 \\
\hline Carvão activado modificado & ACSA & $\begin{array}{l}\text { Resulta do tratamento de AC com ácido sulfúrico con- } \\
\text { centrado [24] }\end{array}$ \\
\hline Xerogel de carbono & RFX & $\begin{array}{l}\text { Preparado por reacções de polimerização utilizando } \\
\text { resorcinol e formaldeído [25] }\end{array}$ \\
\hline Xerogel de carbono modificado & ACXK & $\begin{array}{l}\text { Resulta do tratamento a seco de RFX com hidróxido } \\
\text { de potássio [25] }\end{array}$ \\
\hline Nanotubos de carbono de paredes múltiplas & MWCNT & Sigma-Aldrich, ref. 677248 \\
\hline Material de carbono à base de glicerol & GBCM & $\begin{array}{l}\text { Preparado por carbonização parcial de glicerol com } \\
\text { ácido sulfúrico concentrado [26] }\end{array}$ \\
\hline $\begin{array}{l}\text { Espécies de ferro }\left(\mathrm{Fe}^{2+} \text { e } \mathrm{Fe}^{3+}\right) \text { em fase ho- } \\
\text { mogénea }\end{array}$ & $\mathrm{Fe}(\mathrm{II}) / \mathrm{Fe}(\mathrm{III})$ & $\begin{array}{l}\text { Nitrato de ferro nona-hidratado utilizado como pre- } \\
\text { cursor }^{\text {a }} \text { de iões } \mathrm{Fe}^{3+} \text { [26] }\end{array}$ \\
\hline Fe suportado em carvão activado & $\mathbf{F e} / \mathrm{AC}$ & $\begin{array}{l}\text { Resulta da impregnação incipiente de AC com precur- } \\
\text { sor de ferro }{ }^{\mathrm{a}} \text { (4\% de } \mathrm{Fe}(\mathrm{III}) \text { em massa) e calcinação a } \\
200^{\circ} \mathrm{C}[26]\end{array}$ \\
\hline
\end{tabular}

a Por precursor de ferro, entenda-se o composto nitrato de ferro(III) nona-hidratado que fornece a espécie metálica a impregnar na superfície do material. 


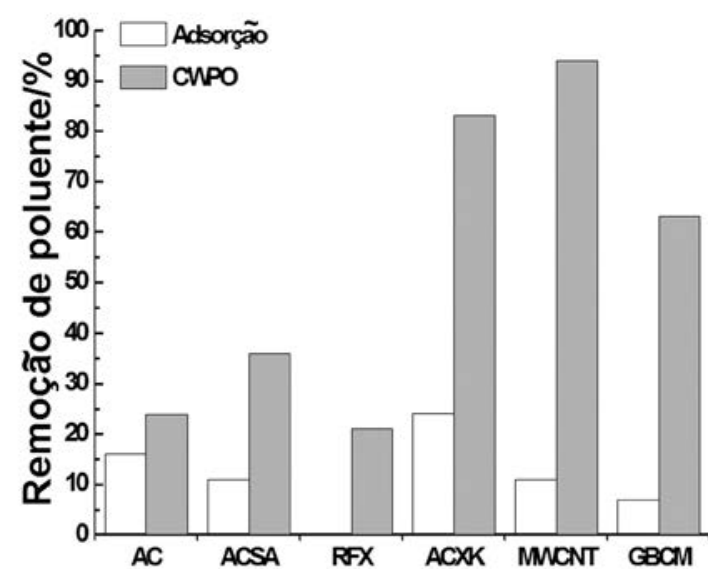

Figura 2 - Remoções de Chromotrope-2R (AC, ACSA, RFX e ACXK) e de 2-NP (MWCNT e GBCM) obtidas após 150 min em ensaios de adsorção e de CWPO desenvolvidos com diferentes materiais de carbono, considerando $T=50^{\circ} \mathrm{C}, \mathrm{pH}=3,\left[\mathrm{H}_{2} \mathrm{O}_{2}\right]_{0}=34,6 \mathrm{mmol} \mathrm{L}^{-1}$ (no caso dos ensaios de CWPO) e uma carga de adsorvente/catalisador de 0,5 $\mathrm{g} \mathrm{L}^{-1}$, no caso do AC e do ACSA, e de $0,1 \mathrm{~g} \mathrm{~L}^{-1}$ para os restantes materiais. Ensaios realizados num reactor de vidro sob agitação e com controlo de temperatura, contendo $100 \mathrm{mg} \mathrm{L}^{-1}$ de poluente no início de cada ensaio

para este processo, através de uma comparação entre a utilização de $\mathrm{Fe}(\mathrm{II}) / \mathrm{Fe}(\mathrm{III})$ como catalisador homogéneo, Fe/AC como catalisador heterogéneo com espécies de ferro suportadas e GBCM como catalisador heterogéneo sem espécies metálicas suportadas. O estudo comparou os resultados sobre soluções de 2-NP e $\mathrm{H}_{2} \mathrm{O}_{2}$ (branco), i.e. sem catalisador, e em diferentes ensaios de CWPO utilizando $\mathrm{Fe}(\mathrm{II}) / \mathrm{Fe}(\mathrm{III}), \mathrm{Fe} / \mathrm{AC}$ e GBCM. No caso do ensaio homogéneo usou-se uma concentração de iões $\mathrm{Fe}^{3+}$ equivalente à quantidade de espécies de ferro lixiviadas durante o ensaio com o catalisador Fe/AC (nomeadamente $0,745 \mathrm{mg} \mathrm{L}^{-1}$, determinada por absorção atómica).

Da análise dos resultados apresentados na Figura 3 verifica-se que a decomposição de 2-NP promovida por $\mathrm{H}_{2} \mathrm{O}_{2}$ na ausência de catalisador é significativamente inferior à

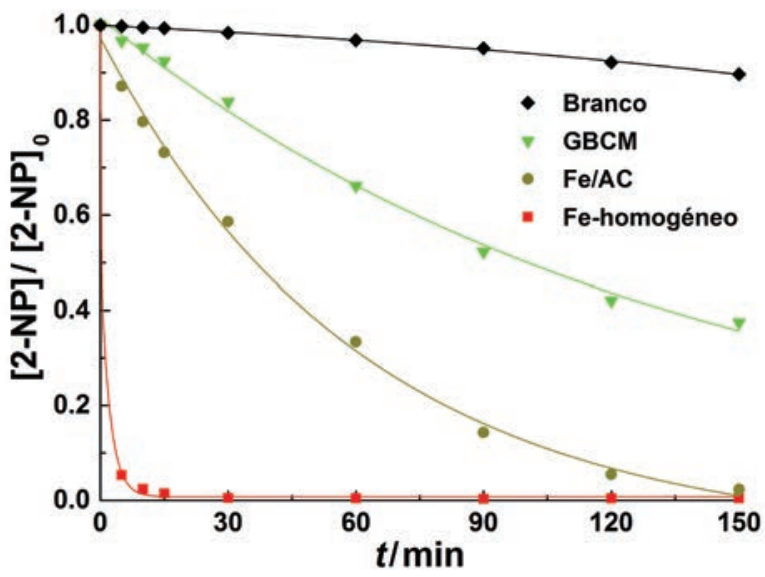

Figura 3 - Remoção de 2-NP na presença de diferentes catalisadores (Fe(II)/Fe(III), Fe/AC e GBCM) para CWPO e na ausência de catalisador (branco), a $T=50^{\circ} \mathrm{C}, \mathrm{pH}=3,\left[\mathrm{H}_{2} \mathrm{O}_{2}\right]_{0}=34,6 \mathrm{mmol} \mathrm{L}^{-1}$. No ensaio homogéneo, $\left[\mathrm{Fe}^{3+}\right]=0,745 \mathrm{mg} \mathrm{L}{ }^{-1}$, e nos ensaios heterogéneos $0,1 \mathrm{~g} \mathrm{~L}^{-1}$ de Fe/AC ou de GBCM. Ensaios realizados num reactor de vidro sob agitação e com controlo de temperatura, contendo $100 \mathrm{mg} \mathrm{L}^{-1}$ de 2-NP no início de cada ensaio decomposição observada na presença de catalisador e que a utilização de Fe-homogéneo leva a uma remoção de 99\% da concentração inicial de 2-NP em apenas 15 min de reacção. Estes resultados levam a concluir que a actividade do catalisador $\mathrm{Fe} / \mathrm{AC}$ se deve fundamentalmente à actividade das espécies de ferro que lixiviam para a solução e não à actividade das espécies de ferro que permanecem suportadas.

Quanto à utilização do GBCM como catalisador, livre de espécies metálicas suportadas, verifica-se uma remoção significativa de 2-NP, que pese embora seja inferior à obtida no processo homogéneo, é bastante interessante, justificando um estudo mais aprofundado com este material com vista a melhor compreender os mecanismos envolvidos no processo de CWPO na presença de GBCM. Esse estudo, bem como a caracterização da estabilidade e regenerabilidade do material, encontra-se presentemente em curso.

\section{CONSIDERAÇÕES FINAIS}

A análise das principais motivações que têm originado progressos no desenvolvimento de catalisadores para o processo de CWPO, com vista ao tratamento de compostos orgânicos presentes em solução aquosa, permite estabelecer as principais vantagens e limitações decorrentes da utilização de catalisadores homogéneos ou heterogéneos.

A utilização de $\mathrm{Fe}^{2+}$ (processo de Fenton) e de $\mathrm{Fe}^{3+}$ como catalisadores homogéneos permite a rápida oxidação de uma grande diversidade de compostos orgânicos, contudo é acompanhada da contaminação das águas tratadas com espécies de ferro dissolvidas. Nestes casos é absolutamente indispensável a existência de um passo de separação adicional para a sua separação sempre que os respectivos valores legislados para descarga de águas não sejam respeitados.

A utilização de catalisadores heterogéneos envolvendo espécies metálicas suportadas permite a separação dos materiais sólidos no final do processo, mas frequentemente estes materiais revelam instabilidade, resultando em lixiviação das espécies metálicas para a solução.

Mais recentemente foi verificado que materiais de carbono sem espécies metálicas suportadas, apesar de apresentarem menor actividade catalítica do que os catalisadores homogéneos e heterogéneos envolvendo espécies metálicas activas, são materiais activos e promissores para o processo de CWPO.

A resenha histórica apresentada no presente trabalho mostra uma clara tendência nesta área de investigação para o desenvolvimento de materiais de carbono sem espécies metálicas suportadas. Nesse sentido podem ser identificadas duas vias de investigação complementares, nomeadamente a introdução de modificações na química superficial de materiais de carbono e a síntese de materiais de carbono intrinsecamente mais activos para o processo de CWPO. 
Apenas uma ressalva para a síntese de nanocompósitos contendo espécies de ferro na sua composição, que sendo uma área ainda pouco explorada em CWPO, poderá também constituir uma alternativa viável de futuro.

\section{Agradecimentos}

Trabalho apoiado pelo projecto PTDC/AAC-AMB/110088/ 2009 e parcialmente pelos projectos PEst-C/EQB/ LA0020/2013 e NORTE-07-0124-FEDER-0000015, cofinanciados pelo FEDER através do COMPETE, QREN e ON2, e pela Fundação para a Ciência e a Tecnologia (FCT). AMTS agradece o apoio concedido ao abrigo do programa Investigador FCT 2013, financiado pelo Fundo Social Europeu e o Programa Operacional Potencial Humano.

\section{REFERÊNCIAS}

[1] M.M. Fonseca, J.A. Teixeira, "Reactores biológicos - fundamentos e aplicações”, Lidel - edições técnicas, Lda., Lisboa, 2007

[2] G. Tchobanoglous, F.L. Burton, H.D. Stensel, "Wastewater engineering: treatment and reuse”, Fourth edition, Metcalf \& Eddy Inc., McGraw-Hill Companies, New York, 2003

[3] C.W. Jones, “Applications of hydrogen peroxide and derivatives”, The Royal Society of Chemistry, Cambridge, UK, 1999

[4] H.J.H. Fenton, J. Chem. Soc., Trans. 65 (1894) 899-910

[5] F. Haber, J. Weiss, Proc. R. Soc. A 147 (1934) 332-351

[6] W.G. Barb, J.H. Baxendale, P. George, K.R. Hargrave, Trans. Faraday Soc. 47 (1951) 462-500

[7] W.G. Barb, J.H. Baxendale, P. George, K.R. Hargrave, Trans. Faraday Soc 47 (1951) 591-616

[8] P.R. Gogate, A.B. Pandit, Adv. Environ. Res. 8 (2004) 501$-551$

[9] S. Navalon, M. Alvaro, H. Garcia, Appl. Catal. B-Environ. 99 (2010) 1-26

[10] USATSDR, "Medical management guidelines for hydrogen peroxide”, Agency for Toxic Substances and Disease Registry, Atlanta, U.S., 2011

[11] Decreto-Lei n. ${ }^{\circ}$ 236/98 de 1 de Agosto, Diário da República - I Série - A, n. ${ }^{\circ} 176$ - 1-8-1998
[12] J. Barrault, J.M. Tatibouët, N. Papayannakos, C. R. Acad. Sci. - Series IIC 3 (2000) 777-783

[13] P. Serp, J.L. Figueiredo, “Carbon materials for catalysis”, John Wiley \& Sons, Inc., Hoboken, New Jersey, 2009

[14] J.L. Figueiredo, J. Mater. Chem. A 1 (2013) 9351-9364

[15] P. Serp, M. Corrias, P. Kalck, Appl. Catal. A-Gen. 253 (2003) 337-358

[16] J.H. Ramirez, F.J. Maldonado-Hódar, A.F. Pérez-Cadenas, C. Moreno-Castilla, C.A. Costa, L.M. Madeira, Appl. Catal. B-Environ. 75 (2007) 312-323

[17] J.A. Zazo, J.A. Casas, A.F. Mohedano, J.J. Rodríguez, Appl. Catal. B-Environ. 65 (2006) 261-268

[18] S. Navalon, A. Dhakshinamoorthy, M. Alvaro, H. Garcia, ChemSusChem 4 (2011) 1712-1730

[19] F. Lücking, H. Köser, M. Jank, A. Ritter, Water Res. 32 (1998) 2607-2614

[20] H.T. Gomes, S.M. Miranda, M.J. Sampaio, J.L. Figueiredo, A.M.T. Silva, J.L. Faria, Appl. Catal. B-Environ. 106 (2011) 390-397

[21] A. Rey, A. Bahamonde, J.A. Casas, J.J. Rodríguez, Water Sci. Technol. 61 (2010) 2769-2778

[22] O. Taran, E. Polyanskaya, O. Ogorodnikova, V. Kuznetsov, V. Parmon, M. Besson, C. Descorme, Appl. Catal. A-Gen. 387 (2010) 55-66

[23] A. Rey, J.A. Zazo, J.A. Casas, A. Bahamonde, J.J. Rodríguez, Appl. Catal. A-Gen. 402 (2011) 146-155

[24] H.T. Gomes, S.M. Miranda, M.J. Sampaio, A.M.T. Silva, J.L. Faria, Catal. Today 151 (2010) 153-158

[25] R.S. Ribeiro, N.A. Fathy, A.A. Attia, A.M.T. Silva, J.L. Faria, H.T. Gomes, Chem. Eng. J. 195/196 (2012) 112-121

[26] R.S. Ribeiro, A.M.T. Silva, J.L. Figueiredo, J.L. Faria, H.T. Gomes, Appl. Catal. B-Environ. 140 (2013) 356-362

[27] V.P. Santos, M.F.R. Pereira, P.C.C. Faria, J.J.M. Órfão, J. Hazard. Mater. 162 (2009) 736-742

[28] M. A. Salam, M.A. Gabal, A.Y. Obaid, Synthetic Met. 161 (2012) 2651-2658

[29] J. Su, M. Cao, L. Ren, C. Hu, J. Phys. Chem. C 115 (2011) 14469-14477

[30] J. Li, J. Gu, H. Li, Y. Liang, Y. Hao, X. Sun, L. Wang, Micropor. Mesopor. Mat. 128 (2010) 144-149

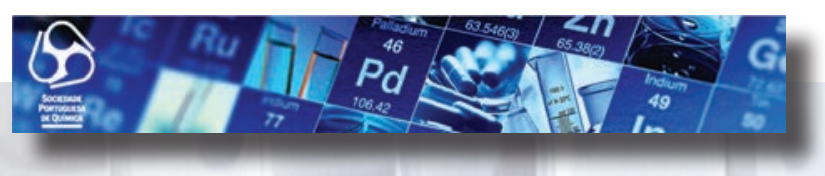

Torne-se Sócio da Sociedade Portuguesa de Química e beneficie de:

- Pertencer a uma comunidade científica dinâmica;

- Receber o boletim "QUÍMICA";

- Descontos nos Encontros promovidos pela SPQ:

- Descontos nas publicações da SPQ;

- Protocolos assinados entre a SPQ e outras entidades;

- Participar na promoção da Química;

- Apoiar uma Sociedade Científica.

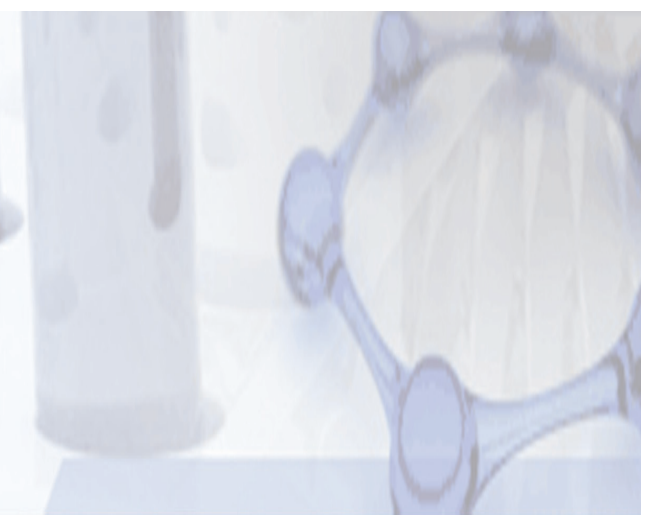

